\title{
Thermal Stability of Residual Stresses in Differently Deep Rolled Surface Layers of Steel SAE 1045
}

\author{
Stephanie Saalfeld, Thomas Wegener, Berthold Scholtes, and Thomas Niendorf
}

\author{
Submitted: 3 February 2021 / Revised: 6 April 2021 / Accepted: 11 April 2021 / Published online: 7 May 2021
}

\begin{abstract}
The stability of compressive residual stresses generated by deep rolling plays a decisive role on the fatigue behavior of specimens and components, respectively. In this regard, deep rolling at elevated temperature has proven to be very effective in stabilizing residual stresses when fatigue analysis is conducted at ambient temperature. However, since residual stresses can be affected not only by plastic deformation but also when thermal energy is provided, it is necessary to analyze the influence of temperature and time on the relaxation behavior of residual stresses at elevated temperature. To evaluate the effect of deep rolling at elevated temperatures on stability limits under thermal as well as combined thermo-mechanical loads, the present work introduces and discusses the results of investigations on the thermal stability of residual stresses in differently deep rolled material conditions of the steel SAE 1045.
\end{abstract}

Keywords aging, deep rolling, fatigue, thermal loading, residual stress

\section{Introduction}

The influence of temperature on the fatigue behavior is of utmost importance for many applications. Components such as steam or gas turbines, engine components in automotive engineering or contacts in computer technology are subjected to cyclic temperature and load changes during operation (Ref 1,2). Structural elements being exposed to mechanical loads at high temperatures are characterized by inferior durability compared to components stressed at room temperature (Ref 3 ). Numerous models for calculating and estimating fatigue life can be found, e.g., summarized in (Ref 4). At elevated temperatures, several changes in material states can occur promoted by recovery, recrystallization, grain coarsening or phase transformation. All these changes are influenced not only by temperature but also by mechanical stresses and strains, time, as well as environmental conditions (Ref 5,6). In all cases, diffusion significantly contributes to changes seen in the microstructure (Ref 7,8 ). Since diffusion at homologous temperatures $\left(T_{h}\right)$ above 0.4 (i.e., at application temperatures above $0.4 \times \mathrm{T}_{\mathrm{m}}$, where $\mathrm{T}_{\mathrm{m}}$ is the melting point in $[\mathrm{K}]$ ) accounts for a relevant contribution to the above mentioned changes, data for many materials are only available for this high temperature regime. In view of the melting point of most steels (as well as Ni- and Co-alloys), high-temperature applications are considered to be above $500{ }^{\circ} \mathrm{C}$. For temperatures below, i.e., the temperature window ranging from ambient temperature to $500{ }^{\circ} \mathrm{C}$, limited data are

Stephanie Saalfeld, Thomas Wegener, Berthold Scholtes, and Thomas Niendorf, Institute of Materials Engineering-Metallic Materials, University of Kassel, Mönchebergstraße 3, 34125 Kassel, Germany. Contact e-mails: stephaniesaalfeld@gmail.com, t.wegener@uni-kassel.de, scholtes@uni-kassel.de, and niendorf@unikassel.de. available even for widely studied steels as SAE 1045. Thus, prediction of process-microstructure-property relations in this intermediate, elevated temperature regime cannot be done in a straightforward manner.

In the case of carbon steels, the temperature dependence is strongly affected by dynamic strain aging processes (Ref 9). Thereby, the dislocation movement is blocked by interstitially dissolved carbon atoms. A strong decrease of the plastic strain in certain temperature windows has been dedicated to the maximum impact of dynamic strain aging (Ref 9), being highly affected by the actual strain rate (carbon atoms diffuse at the velocity of dislocations in this window). A decrease in strength and concomitantly an increase in ductility apply with further increasing temperature (Ref 10), so that increased plastic strain amplitudes must be expected under fatigue loading.

Investigations already published several years ago (Ref 11-15) highlighted the prevailing research gap. In all these studies, only one single surface treatment technique was employed, i.e., shot peening conducted at ambient temperature. It was shown that strain aging effects indeed have an influence on the stability of residual stresses under thermal and cyclic loading. However, the impact of shot peening at elevated temperatures on the microstructural stability in case of thermal and cyclic loading was not investigated. Likewise, studies focusing on residual stress stability under these loading conditions in deep rolled material states, where deep rolling was conducted at different temperatures, are not available. Thus, investigations on the influence of deep rolling temperatures on the residual stress stability during subsequent thermal and/or cyclic loading are lacking. From direct comparison of shot peened and deep rolled conditions (focusing on fatigue properties at ambient temperature), it can be deduced that deep rolling is much more effective in establishing surface conditions being characterized by highest compressive residual stresses (absolute values and penetration depth), smooth surface appearance and eventually superior fatigue performance. In order to reveal stability limits of the treated conditions and to study the elementary mechanisms leading to degradation in superior material conditions the present work, thus, only considered deep rolled steel SAE 1045. 


\section{Material and Methods}

The material in focus was a quenched and tempered steel SAE 1045 with the chemical composition (determined by optical emission spectroscopy) given in Table 1. For all tests tension-compression specimens with a total length of $120 \mathrm{~mm}$, a gauge length of $18 \mathrm{~mm}$ and a gauge diameter of $6 \mathrm{~mm}$ were used. All specimens were heat treated first, whereby the heat treatment was separated into inductive hardening $\left(900{ }^{\circ} \mathrm{C}, 1 \mathrm{~s}\right.$, quenched in water containing $10 \%$ polymer) and tempering in a conventional furnace $\left(400^{\circ} \mathrm{C}, 1 \mathrm{~h}\right.$, air cooling). This condition constituted the initial state for all further treatments.

After heat treatment, the deep rolling process was carried out at room temperature (named $\mathrm{dr} 23$ in the remainder of the text), $250{ }^{\circ} \mathrm{C}$ (named $\mathrm{dr} 250$ in the remainder of the text) and $400{ }^{\circ} \mathrm{C}$ (named $\mathrm{dr} 400$ in the remainder of the text) using a pneumatic deep rolling tool of type Ecoroll GS-40F-R2.5-HX and an induction heater controlled by a pyrometer. The deep rolling force was $1.5 \mathrm{kN}$ ( $3 \mathrm{bar}$ ) and a single pass process was applied. In addition, according to preliminary studies, the speed of the deep rolling tool and the feed rate were set to $80 \mathrm{rpm}$ and $0.1 \mathrm{~mm} / \mathrm{rev}$. For further details on the setup the reader is referred to (Ref 16).

Some specimens was additionally heat treated after deep rolling at aging temperatures of $250{ }^{\circ} \mathrm{C}, 400{ }^{\circ} \mathrm{C}$ and $600{ }^{\circ} \mathrm{C}$ for different aging times of $30 \mathrm{~min}, 1 \mathrm{~h}$ and $10 \mathrm{~h}$.

For the hardness measurements, a Struers indentation system (DuraScan70G5) was used. The tests were carried out using the Vickers-method with a test load of $4.9 \mathrm{~N}$ and a holding time of $15 \mathrm{~s}$.

Fatigue tests were carried out using a servo-hydraulic test rig (Schenck type PC160) at room temperature and $300{ }^{\circ} \mathrm{C}$. Tests were done under stress controlled uniaxial tensioncompression loading with a stress ratio of $\mathrm{R}=-1$ and a test frequency of $15 \mathrm{~Hz}$. The residual stress depth profiles of the tension-compression specimens were measured by $\mathrm{x}$-ray diffraction (XRD) in longitudinal and circumferential direction using a $\psi$-diffractometer of type Huber 424-10450 in the range of $150^{\circ} \leq 2 \theta \leq 162^{\circ}$ at $11 \psi$-angles between $-45^{\circ}$ and $+45^{\circ}$ on the $\{211\}$ planes of ferrite using $\mathrm{CrK} \alpha$ radiation. The stress evaluation was carried out applying the $\sin ^{2}$ $\psi$-method using the elastic constants $1 / 2 \mathrm{~s}_{2}=6.09 \times$ $10^{-6} \mathrm{~mm}^{2} / \mathrm{N}$ and $2 \theta_{0}=156.07^{\circ}$. To analyze residual stress profiles, successive electrochemical removal of the surface layers was applied. Corrections for the effect of layer removal on residual stresses were investigated and found to be minimal. Differences in residual stress profiles for different deep rolling temperatures were very similar for both uncorrected and corrected data.

Table 1 Chemical composition of the SAE 1045 obtained by optical emission sprectroscopy (wt.\%)

\begin{tabular}{cccccccc}
\hline $\mathbf{C}$ & Mn & Si & P & S & Ni & Cr & Mo \\
\hline 0.49 & 0.59 & 0.21 & 0.019 & 0.02 & 0.02 & 0.03 & 0.005 \\
\hline
\end{tabular}

\section{Results and Discussion}

In order to be able to assess the changes of the residual stresses in the surface layer during thermal loading, the process induced residual stresses have been firstly analyzed in their respective initial states. Figure 1 provides for an overview of the residual stresses and integral width values in the longitudinal and circumferential direction for all specimen conditions considered. The residual stress depth profiles in Fig. 1(a) show maximum values directly at the surface for deep rolling temperatures of $23{ }^{\circ} \mathrm{C}$ and $250{ }^{\circ} \mathrm{C}$ whereas deep rolling at $400{ }^{\circ} \mathrm{C}$ leads to a maximum residual stress value at a depth of $0.2 \mathrm{~mm}$. In general, maximum values of $-675 \mathrm{MPa}(\mathrm{dr} 250)$, $-615 \mathrm{MPa}(\mathrm{dr} 23)$ and $-255 \mathrm{MPa}(\mathrm{dr} 400)$ can be seen for the longitudinal direction. At increasing surface distance, the residual stresses decrease continuously and reach values below $-100 \mathrm{MPa}$ at a depth of about $1 \mathrm{~mm}$. In the courses of the circumferential residual stresses shown in Fig. 1(b), a second maximum beneath the surface at depths values of $0.4 \mathrm{~mm}$ (dr250), $0.6 \mathrm{~mm}(\mathrm{dr} 23)$ and $0.8 \mathrm{~mm}(\mathrm{dr} 400)$ can be identified. Again, the specimens deep rolled at $23{ }^{\circ} \mathrm{C}$ and $250{ }^{\circ} \mathrm{C}$ are characterized by highest residual stresses as compared to the counterpart condition.

The corresponding integral width values shown in Fig. 1(c) indicate a high degree of work hardening revealed by strongly increased integral width values at the surface for two conditions, i.e., $\mathrm{dr} 250$ and $\mathrm{dr} 23$. As can be deduced from the course of the curves, plastic deformation is effective up to different depth values, e.g., up to a maximum depth of $0.6 \mathrm{~mm}$ in the condition deep rolled at ambient temperature. Although the lowest absolute integral width values are generally obtained for the dr400 condition, the near surface area of this condition (with a depth of $1 \mathrm{~mm}$ ) is effectively influenced by the deep rolling process as well.

Under thermal load, the condition of the material and in particular the near surface area, which was primarily affected by surface treatment, can be strongly altered (Ref 17). The results described below are intended to highlight the importance of selecting a suitable deep rolling temperature with regard to hardness, residual stresses as well as fatigue lives.

The results after thermal aging are presented in Fig. 2. Figure 2(a) exemplarily shows the changes in the surface hardness (distance from the surface: $0.10 \mathrm{~mm}$ ) for two aging conditions, i.e., aging temperatures of $250^{\circ} \mathrm{C}$ and $400{ }^{\circ} \mathrm{C}$ at an aging time of 10 hours. Obviously, hardness evolution is strongly influenced by the relation between aging and deep rolling temperature. As soon as the aging temperature exceeds the deep rolling temperature, a tempering effect, i.e., a significant decrease of hardness, can be seen (Ref 18). Thus, the $\mathrm{dr} 23$ condition is characterized by a decrease of hardness for both aging treatments, while the dr250 condition only shows softening upon aging at $400{ }^{\circ} \mathrm{C}$. Hardness in the $\mathrm{dr} 400$ remains almost unaffected. In general, this behavior can be rationalized based on microstructural evolution during the deep rolling treatment. The deep rolling process including heating and cooling of the specimen takes about $8 \mathrm{~min}$. In the course of time, carbides are formed at the deep rolling temperature of $400{ }^{\circ} \mathrm{C}$ (Ref 19, 20) eventually leading to additional precipitation hardening. This is thought to be the most reasonable explanation for the higher stability of surface hardness for $\mathrm{dr} 400$. However, compared to dr23 and dr250, smaller values can be observed in the unloaded state for $\mathrm{dr} 400$. This kind of inferior 

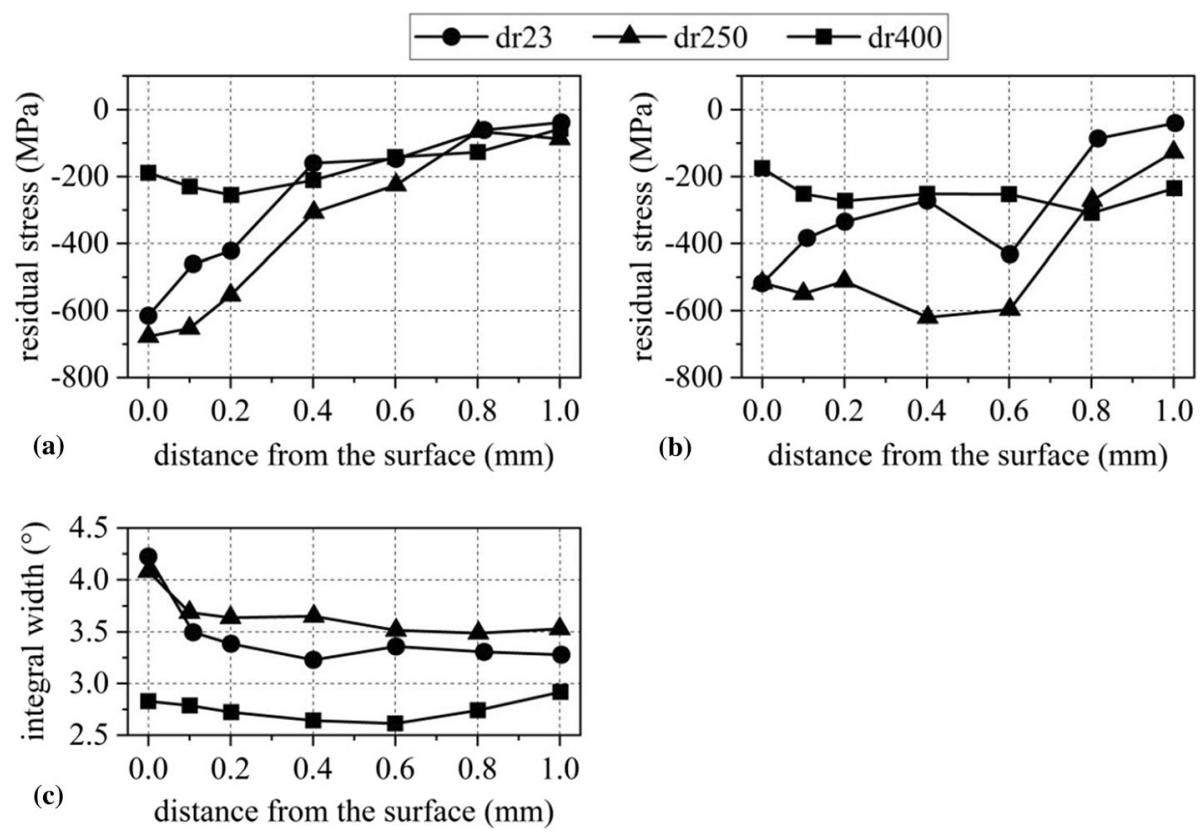

Fig. 1 Residual stress profiles in (a) longitudinal direction and (b) circumferential direction with corresponding integral width values in (c) for differently deep rolled conditions

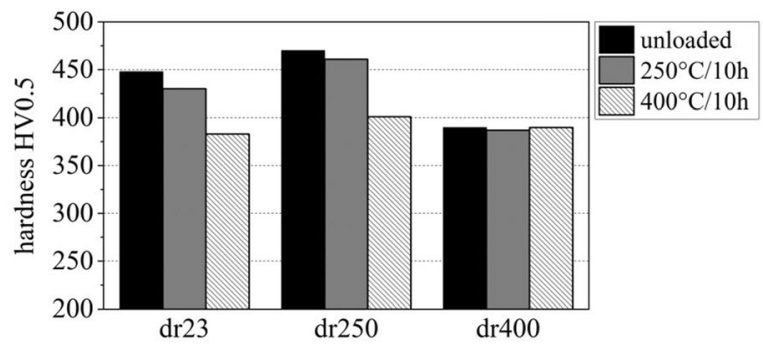

(a) surface layer in a depth of $0.10 \mathrm{~mm}$

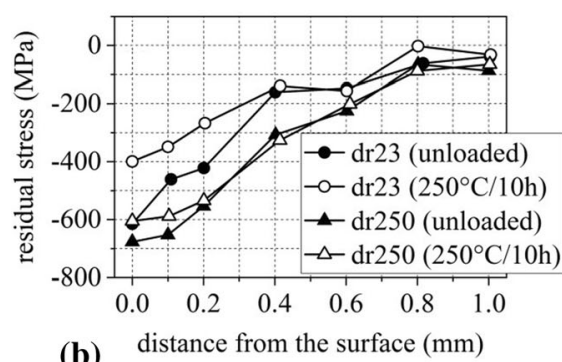

(b) distance from the surface $(\mathrm{mm})$

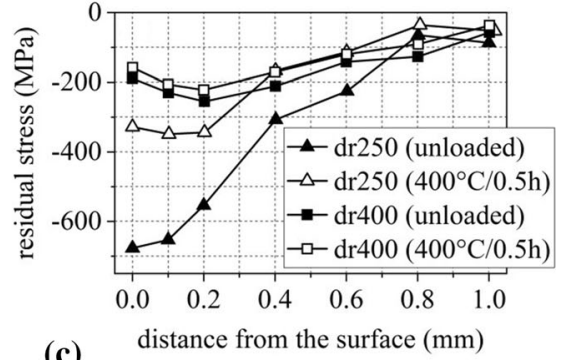

(c)

Fig. 2 (a) Surface hardness, (b) and (c) residual stress depth profiles (longitudinal direction) as directly established by deep rolling (referred to as unloaded) as compared to conditions after aging at temperatures of $250{ }^{\circ} \mathrm{C}$ and $400{ }^{\circ} \mathrm{C}$ for different holding periods (see text for details)

properties can be attributed to the non-altered deep rolling parameters. Usually, the deep rolling force has to be adapted to the deep rolling temperature, however, this was not the major goal of present work. Thus, only one set of parameters (i.e., rolling force and number of passes) was used.

When considering the residual stresses, very similar correlations can be deduced. Figure 2(b) and Fig. 2(c) clearly show that the deep rolling temperature also has an influence on the stability of the residual compressive stresses. If the aging temperature exceeds the deep rolling temperature (see Fig. 2b: dr23 and Fig. 2c: dr250), residual stresses are significantly reduced. The dislocation structures being established by the deep rolling treatment are not stable, rearrangement by localized plasticity leads to the changes seen. Degradation is most pronounced where the highest residual stresses prevail, i.e., directly at the surface, whereas areas below having lower initial residual stresses are almost unaffected. If the deep rolling temperature and the aging temperature are on the same level (see Fig. 2b: dr250 and Fig. 2c: dr400) the residual stresses demonstrate good stability, eventually indicating stable dislocation structures. Obviously, the absolute temperature as well as the temperature offset between deep rolling temperature and aging temperature have a pronounced effect on surface residual stresses. For the $\mathrm{dr} 23$ condition aged at $250{ }^{\circ} \mathrm{C}$ residual stresses 
are reduced by about $200 \mathrm{MPa}$, whereas for the $\mathrm{dr} 250$ condition aged at $400{ }^{\circ} \mathrm{C}$ a decrease of about $350 \mathrm{MPa}$ is seen. Concomitantly, in the latter specimen residual stresses below the surface are decreased.

In addition to load free thermal aging, the influence of the deep rolling temperature on microstructure stability under cyclic mechanical loading was investigated at testing temperatures up to $300{ }^{\circ} \mathrm{C}$. Results were analyzed with respect to fatigue life, cyclic plastic deformation and residual stress stability. Figure 3 shows the fatigue life diagrams for testing temperatures of $23{ }^{\circ} \mathrm{C}$ and $300{ }^{\circ} \mathrm{C}$. Under a testing temperature of $300{ }^{\circ} \mathrm{C}$, the average fatigue lives for all material conditions considered are reduced. As already shown for the aging tests without superimposed mechanical load, clear correlations between the deep rolling temperature and the test temperature can be deduced. For dr23 (Fig. 3a) and dr250 (Fig. 3b), the deep rolling temperature is below the test temperature of $300{ }^{\circ} \mathrm{C}$, resulting in significantly reduced fatigue lives irrespective of the stress amplitude imposed. Accordingly, lifetimes at the lowest and highest stress amplitude of $600 \mathrm{MPa}$ and 750 $\mathrm{MPa}$ are reduced by factors of approximately ten and five for
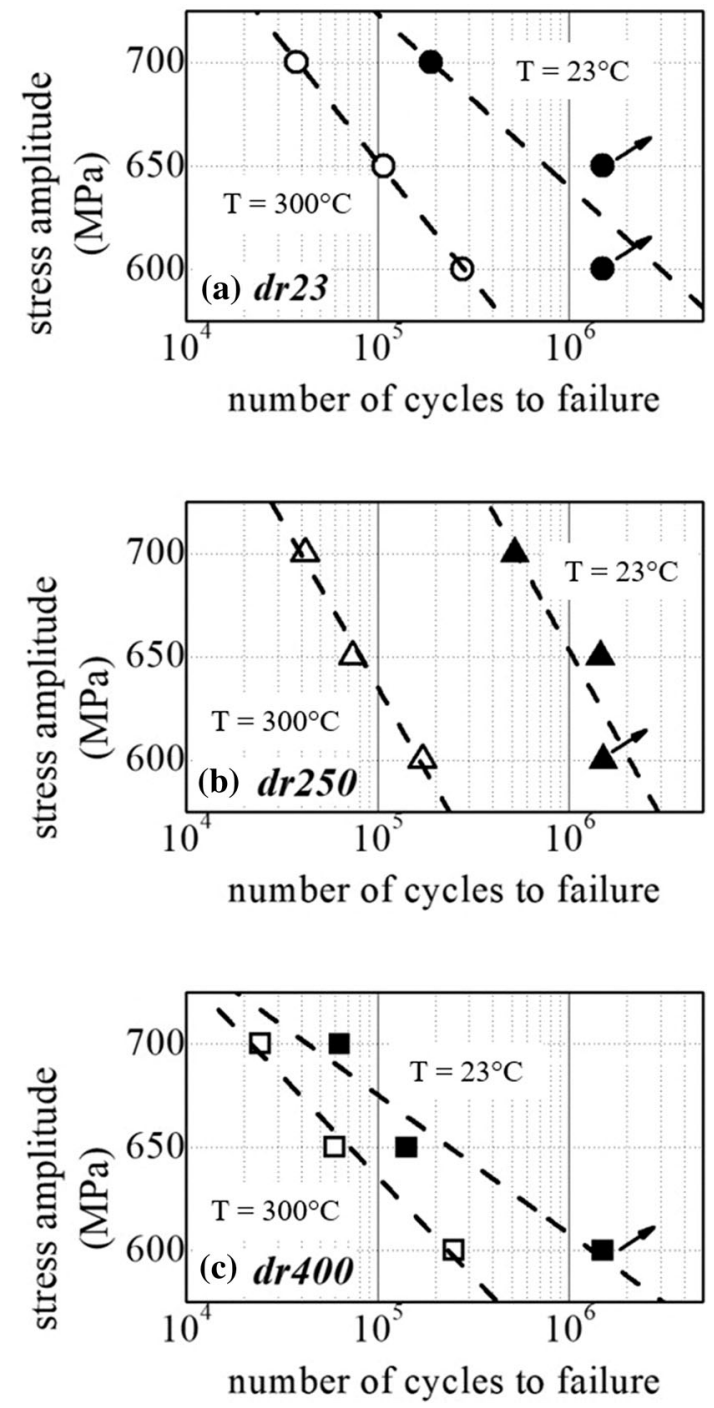

Fig. 3 Fatigue life diagrams of (a) dr23, (b) dr250 and (c) dr400 for fatigue tests at ambient temperature and $300{ }^{\circ} \mathrm{C}$ dr23 and twelve and ten for dr250, respectively. If the testing temperature is below the deep rolling temperature, as it is the case for the dr400 (Fig. 3c) condition considered, still a reduction of fatigue lives can be seen, however, differences are significantly less pronounced, at least for higher stress amplitudes. While testing at $300{ }^{\circ} \mathrm{C}$ reduced the fatigue life by a factor of approximately eight at an amplitude of $600 \mathrm{MPa}$, this factor is only about three at an amplitude of $700 \mathrm{MPa}$. In this case, the influence of the load amplitude and, thus, the resulting dwell time at $300{ }^{\circ} \mathrm{C}$ is of critical importance. Low stress amplitudes result in longer lifetimes as compared to higher amplitudes. Thus, a specimen being fatigued at a relatively low stress amplitude is exposed to the test temperature of $300{ }^{\circ} \mathrm{C}$ for a longer period of time. This time difference influences the fatigue strength rationalizing the more pronounced differences in fatigue life in case of decreasing stress amplitudes. Fracture surface analysis (not shown for sake of brevity) was carried out by optical microscopy (OM) as well as scanning electron microscopy (SEM) supported by energy dispersive x-ray spectroscopy (EDS), revealing local traces of oxidation. However, no clear influence on crack initiation as well as crack propagation could be revealed from analysis.

The changes of the residual stress states during cyclic loading at $300{ }^{\circ} \mathrm{C}$ are shown in Fig. 4 for stress amplitudes of $600 \mathrm{MPa}(\mathrm{a}-\mathrm{c})$ and $700 \mathrm{MPa}(\mathrm{d}-\mathrm{f})$ after 50,000 and 10,000 cycles, respectively. As already expected in the light of the previously discussed results focusing on aging without superimposed mechanical load, a degradation of the residual stresses mainly occurs when the deep rolling temperature was set below the test temperature. Decrease of residual stresses seems to be intensified upon increasing the stress amplitude. This effect can be deduced for the dr23 condition from comparison of Fig. 4(a) and Fig. 4(d) as well as for the dr250 condition from comparison of Fig. 4(b) and Fig. 4(e), respectively. Although tests shown in Fig. 4(d) and Fig. 4(e) have already been stopped after 10,000 cycles, residual stress values are below those determined upon 50,000 cycles at $600 \mathrm{MPa}$. Upon dr400 treatment (Fig. 4c and f), the residual stresses remain stable for $600 \mathrm{MPa}$ and only show a slight reduction when the amplitude is increased to $700 \mathrm{MPa}$. This again confirms that the dr400 condition is characterized by extraordinary microstructural stability not showing significant traces of deterioration of residual stresses even at elevated temperature fatigue loading. Further analysis of microstructure evolution, e.g., provided by transmission electron microscopy, currently is missing and will be subject of future work.

The cyclic plastic response for the different conditions is shown in Figure 5(a-c), exemplarily for a stress amplitude of $700 \mathrm{MPa}$ (curves for the other stress amplitudes reveal similar trends and, thus, are not shown for the sake of brevity). For fatigue testing at ambient temperature, in case of dr23 (Fig. 5a) and dr250 (Fig. 5b), no significant changes in the plastic strain amplitude $\left(\varepsilon_{\text {plast }}\right)$ are observed. Only the dr400 (Fig. 5c) condition shows an increase of $\varepsilon_{\text {plast }}$ in the course of cyclic loading with a stress amplitude of $700 \mathrm{MPa}$, which might be attributed to the increased dislocation density introduced by deep rolling at elevated temperature as well as a more significant contribution of bulk effects. Independent of the material condition, increased plastic strain amplitudes can already be seen in the very first loading cycles at a test temperature of $300{ }^{\circ} \mathrm{C}$. Furthermore, the increased temperature leads to continuous softening being characterized by an exponential trend. Microstructural instability can be regarded 


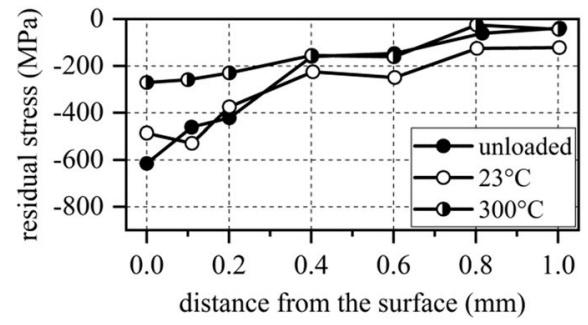

(a) dr23, 600MPa

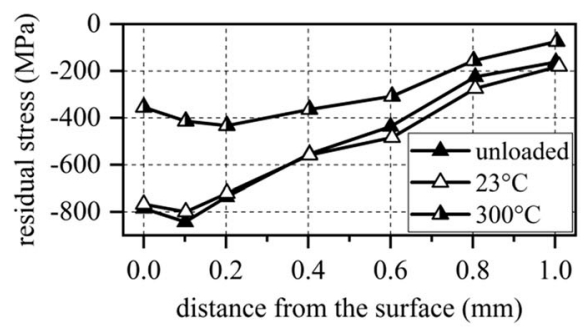

(b) dr250, 600MPa

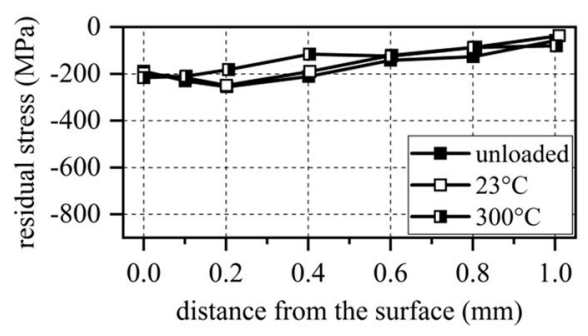

(c) dr400, 600MPa

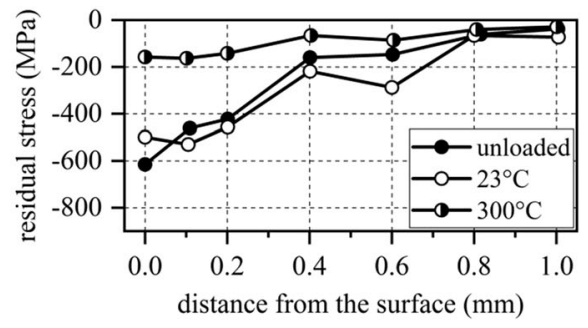

(d) dr23, 700MPa

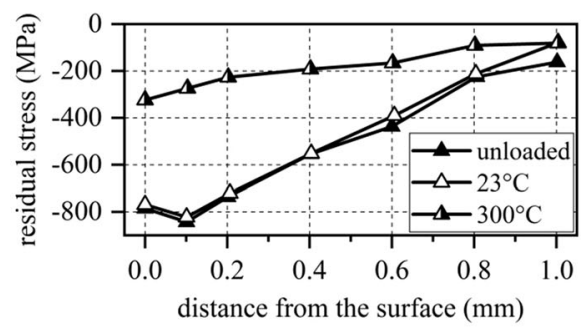

(e) dr250, 700MPa

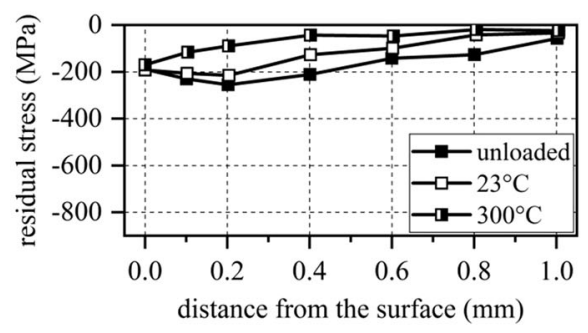

(f) dr400, 700MPa

Fig. 4 Influence of the test temperature on the residual stress stability of the dr23, dr250 and dr400 conditions in initial ("unloaded" in (a-f)) and upon fatigue loading (a-c) with 50,000 cycles at $600 \mathrm{MPa}$ and (d-f) 10,000 cycles at $700 \mathrm{MPa}$. Fatigue tests were conducted at ambient temperature and $300{ }^{\circ} \mathrm{C}$.

as the main reason for the reduced fatigue lives upon elevated temperature testing. From $\mathrm{N}=1,000$, there is a strong increase of the plastic strain amplitude eventually indicating that thermally activated mechanisms play a decisive role.

Surprisingly, similarly high plastic strains are also seen for the dr400 condition at $300{ }^{\circ} \mathrm{C}$, although residual stress depth profiles (Fig. 4) only showed slight changes in this condition. For dr23 and dr250 treatments, the evolution of high plastic strains is seen as expected. These relatively high plastic strains perfectly meet the observed degradation of residual stresses shown in Fig. 4 for these conditions. From these findings it can be concluded that not the absolute value of the plastic strain amplitude determines stability of residual stresses but the difference in the maximum plastic strain amplitude $\left(\Delta \varepsilon_{\text {plast }}\right)$ between test temperatures of $23{ }^{\circ} \mathrm{C}$ and $300{ }^{\circ} \mathrm{C}$, the respective values being highlighted in Fig. 5(a-c). Likewise, due to the steeper gradient, a more pronounced degree of softening can be seen for dr23 and dr250.

Further, the evolution of integral width values at ambient temperature and $300{ }^{\circ} \mathrm{C}$ must be considered as shown in Figure 5(d-f) for a stress amplitude of $700 \mathrm{MPa}$ after 10,000 cycles. For dr23 (Fig. 5d) as well as dr250 (Fig. 5e), decreased integral width values are found for a test temperature of $300{ }^{\circ} \mathrm{C}$ as compared to cyclic loading at ambient temperature, where dr250 shows highest values. This indicates a strong work softening as already deduced from Figure 5(a) and Fig. 5(b).
Since the integral width values upon fatigue at $300{ }^{\circ} \mathrm{C}$ are below those of $23{ }^{\circ} \mathrm{C}$ at any given distance from the surface, it can be concluded that the initially pinned dislocation structures are degraded over the entire near surface zone. As a result, the stability of the microstructure is lost, and fatigue lives are significantly reduced. Only in the case of dr400 (Fig. 5f), the course of the integral widths does not change upon fatigue at $300{ }^{\circ} \mathrm{C}$ (as compared to $23{ }^{\circ} \mathrm{C}$ ). The dislocation structures pinned upon deep rolling are not influenced by cyclic loading and remain completely stable. This is due to the fact that the pinned dislocation structure (additionally influenced by precipitation hardening) is not rearranged. Consequently, lower plastic strain amplitudes and only minor fatigue life reduction result.

\section{Summary and Conclusions}

In summary, the following conclusions can be drawn from the results presented: The investigations on the material behavior of deep rolled surface layers of the quenched and tempered steel SAE 1045 have clearly shown that the deep rolling temperature has a strong influence on microstructure stability. Both, the subsequent aging and fatigue tests (carried out at $300^{\circ} \mathrm{C}$ ) show that a high residual stress stability can only 


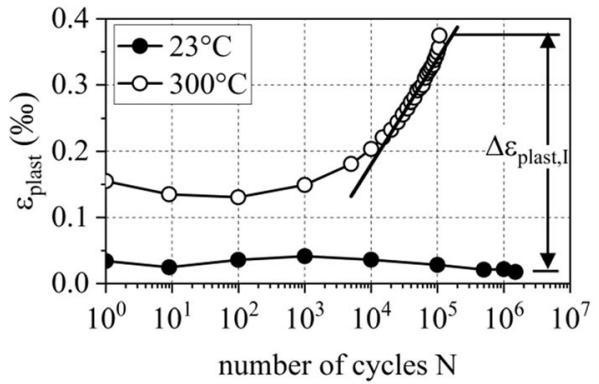

(a) dr23, $\sigma_{\mathrm{a}}=700 \mathrm{MPa}$

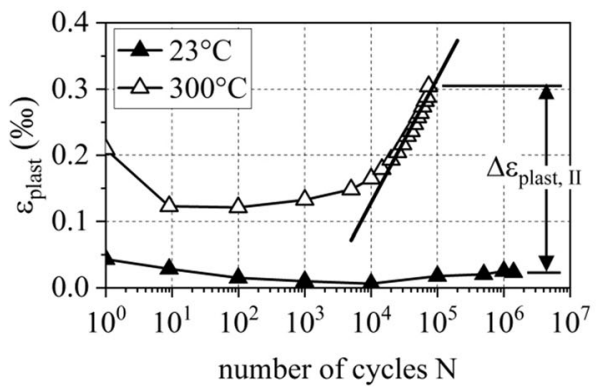

(b) $\operatorname{dr250}, \sigma_{\mathrm{a}}=700 \mathrm{MPa}$

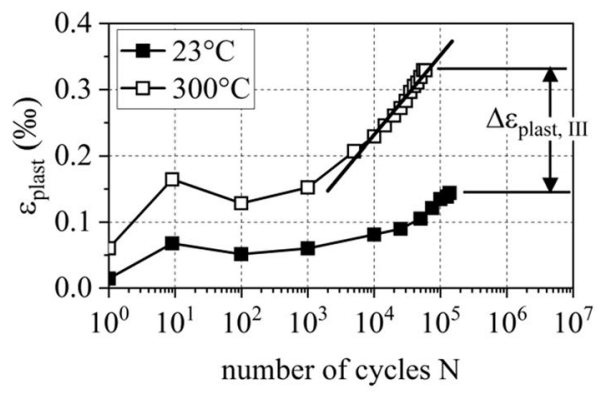

(c) dr400, $\sigma_{\mathrm{a}}=700 \mathrm{MPa}$

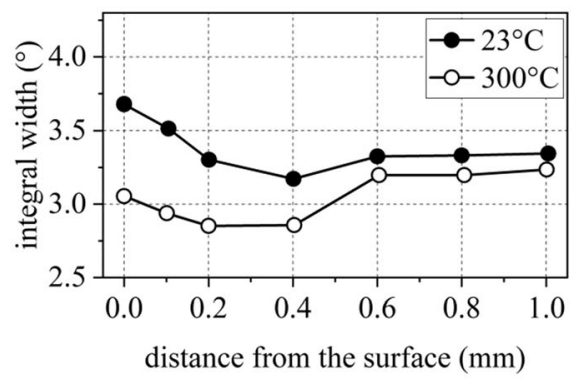

(d) dr23, $\sigma_{\mathrm{a}}=700 \mathrm{MPa}$

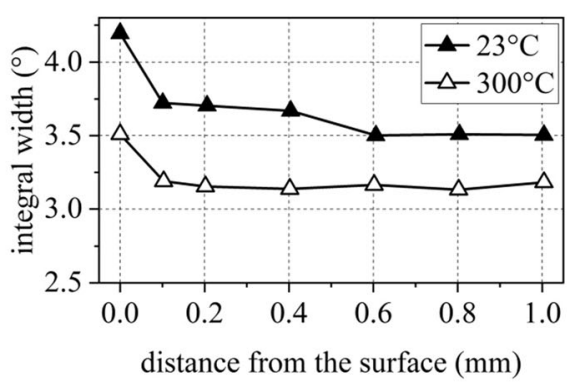

(e) $\operatorname{dr250}, \sigma_{\mathrm{a}}=700 \mathrm{MPa}$

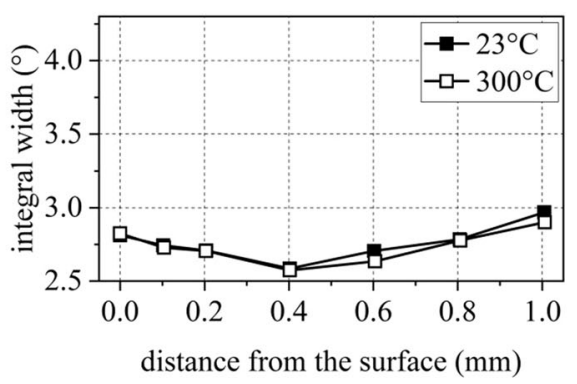

(f) $\mathrm{dr400}, \sigma_{\mathrm{a}}=700 \mathrm{MPa}$

Fig. 5 (a-c) Plastic strain amplitudes and (d-f) integral width values after 10,000 cycles of dr23, dr250 and dr400 cyclically loaded at $23{ }^{\circ} \mathrm{C}$ and $300{ }^{\circ} \mathrm{C}$ with a stress amplitude of $700 \mathrm{MPa}$

be guaranteed if the deep rolling temperature is selected to be above or at least equal to the actual application temperature. The plastic strain evolution as well as the residual stress measurements revealed that higher plastic strain amplitudes and lower integral width values prevail (for deep rolling temperatures below $300{ }^{\circ} \mathrm{C}$ ) after fatigue testing at $300{ }^{\circ} \mathrm{C}$. If the deep rolling temperature and the loading temperature are on the same level, the pinned dislocation structure established by deep rolling can be maintained. Such kind of stability is proven by the absence of changes in the integral width. In addition, the aging tests have shown that with increasing aging temperature and holding time the surface hardness decreased. This additional tempering effect not only reduces the hardness but also influences the compressive residual stress states.

Finally, it has to be mentioned that by only increasing deep rolling temperature (with otherwise constant deep rolling parameters) lower residual compressive stresses are introduced into the near surface zone and, thus, a different starting level is set. For this reason, the deep rolling temperature should be further varied, and the deep rolling parameters adjusted accordingly in order to generate similar initial residual stress states to be able to further analyze the influence of the deep rolling temperature on microstructural stability as a function of aging and cyclic loading conditions.

\section{Acknowledgement}

The authors thank S. Löcker for his experimental support.

\section{Funding} DEAL.

Open Access funding enabled and organized by Projekt

\section{Open Access}

This article is licensed under a Creative Commons Attribution 4.0 International License, which permits use, sharing, adaptation, distribution and reproduction in any medium or format, as long as you give appropriate credit to the original author(s) and the source, 
provide a link to the Creative Commons licence, and indicate if changes were made. The images or other third party material in this article are included in the article's Creative Commons licence, unless indicated otherwise in a credit line to the material. If material is not included in the article's Creative Commons licence and your intended use is not permitted by statutory regulation or exceeds the permitted use, you will need to obtain permission directly from the copyright holder. To view a copy of this licence, visit http://creativecommons.org/licenses/by/4.0/.

\section{References}

1. V.T. Troshchenko, High-cycle Fatigue of High Temperature Alloys under Thermal Cycling Conditions, Fatigue under Thermal and Mechanical Loading Mechanisms Mechanics and Modelling. J. Bressers, L. Rémy, M. Steen, J.L. Vallés Ed., Springer, Dordrecht, 1996, p 179-188

2. H. Sehitoglu Ed., Thermomechanical Fatigue Behavior of Materials, ASTM International, West Conshohocken, 1993

3. D. Munz, Ermüdungsverhalten Metallischer Werkstoffe, DGM Informationsgesellschaft Verlag, Oberursel, 1985, p 441-458. ((in German))

4. R. Danzer, Lebensdauerprognose Hochfester Metallischer Werkstoffe Im Bereich Hoher Temperaturen, Gebrüder Bornträger, Berlin, Stuttgart, 1988. (in German)

5. H.J. Maier, T. Niendorf, and R. Bürgel Eds., Handbuch Hochtemperatur-Werkstofftechnik, 5th ed. Springer Fachmedien, Wiesbaden, 2015 ((in German))

6. V. Schulze Ed., Modern Mechanical Surface Treatment, 1st ed. WileyVCH Verlag GmbH \& Co. KGaA, Weinheim, 2006

7. H. Mehrer Ed., Diffusion in Solids, Springer Verlag GmbH, Berlin, Heidelberg, 2007

8. J.F. Shackelford Ed., Introduction to Materials Science for Engineers, 7th ed. Prentice Hall, Upper Saddle River, NJ, 2009

9. H.J. Christ and H. Mughrabi, Microstructure and Fatigue, Low Cycle Fatigue and Elasto-Plastic Behaviour of Materials. K.T. Rie Ed., Elsevier Science, London, New York, 1992, p 56-69
10. J. Rösler, H. Harders and M. Bäker, Mechanisches Verhalten Der Werkstoffe, Springer Fachmedien, Wiesbaden, 2016. ((in German))

11. M. Roth, Die thermische Stabilität von Eigenspannungen in kugelgestrahlten Oberflächen, Mater. Sci. Eng. Technol., 1987, 18, p 225-228. ((in German))

12. V. Schulze, F. Burgahn, O. Vöhringer and E. Macherauch, Zum thermischen Abbau von Kugelstrahl-Eigenspannungen bei vergütetem 42CrMo4, Mater. Sci. Eng. Technol., 1993, 24, p 258-267. ((in German))

13. O. Vöhringer, Relaxation of Residual Stresses by Annealing or Mechanical Treatment, Advances in Surface Treatments, 1st ed., A. Niku-Lari Ed., Pergamon Press, Oxford, 1987, p 367-396

14. M.R. James, Relaxation of Residual Stresses. An Overview, Advances in Surface Treatments, 1st ed., A. Niku-Lari Ed., Pergamon Press, Oxford, 1987, p 349-365

15. H. Holzapfel, V. Schulze, O. Vöhringer and E. Macherauch, Residual Stress Relaxation in an AISI 4140 Steel due to Quasistatic and Cyclic Loading at Higher Temperatures, Mater. Sci. Eng., A, 1998, 248, p 918

16. T. Oevermann, S. Saalfeld, T. Niendorf and B. Scholtes, Materials and Process Engineering Aspects of Warm Deep Rolling, Int. J. Microstruct. Mater. Prop., 2017, 12, p 230-238

17. D. Löhe and O. Vöhringer, Stability of Residual Stresses, Handbook of Residual Stress and Deformation of Steel. G.E. Totten, M.A.H. Howes, T. Inoue Ed., ASM International, Ohio, 2002, p 54-69

18. S. Saalfeld, T. Oevermann, T. Niendorf and B. Scholtes, Consequences of Deep Rolling on the Fatigue Behavior of Steel SAE 1045 at High Loading Amplitudes, Int. J. Fatigue, 2019, 118, p 192-201

19. A. Cherif, W. Zinn, B. Scholtes (2011) Integration of a deep rolling process in the heat treatment of SAE 1045 steel a way to reduce and optimize the production chain, Proceeding Shot Peening, pp. 43-48

20. A. Cherif, I. Nikitin, P. Juijerm, W. Zinn and B. Scholtes (2014) Deep rolling at lower and elevated temperatures - Effects and Consequences on Fatigue Behavior, Proceeding Shot Peening, pp. 386-391

Publisher's Note Springer Nature remains neutral with regard to jurisdictional claims in published maps and institutional affiliations. 